\title{
Basic Illocutions of the Modern Greek Subjunctive
}

\author{
Maria Chondrogianni \\ University of Westminster \\ M.N.Chondrogianni@westminster.ac.uk
}

\begin{abstract}
In this paper we present the basic illocutions associated with the Modern Greek Subjunctive. The interface between Morphosyntax, Phonology and Pragmatics is very important in this work: each basic illocution is described in terms of prosodic contour (with relevant Praat illustrations); the optional or necessary presence of the associated negation $\mu \eta(v)$; the use of segmental markers, which provide cues on how a certain utterance is to be interpreted; grammatical tense restrictions, where appropriate, including number and person restrictions; aspectual restrictions, where appropriate; as well as the potential answer provided by an addressee to a question, or a question-like utterance.
\end{abstract}

\section{Introduction}

In this paper we discuss the basic illocutions associated with the Modern Greek (MG) Subjunctive mood which form part of the grammar system. Our aim is to provide a systematic description of the basic illocutions of MG, as expressed in main clauses, based on their formal characteristics i.e. based on distinct markers that have an illocutionary impact. Markers considered include the verb mood; the relevant negation particle; the prosodic contour; the number, person and tense where applicable; the addressee's response, where applicable; and any additional segmental markers that apply.

Our primary objectives, as part of a wider research on the basic illocutions of the MG system, included the specification of the relationship between form (e.g. grammar, verb mood, prosodic contour) and function (basic illocution); and the application of the basic illocution systematic hierarchical classification of propositional and behavioural basic illocutions, as proposed by Hengeveld et al. (2007) in MG. Our secondary objectives involved establishing the formal organisation of the MG verb mood system; as well as establishing the MG primary intonation patterns that operate at the level of utterance.

\section{(cc) BY-NC-ND}


The methodology we followed included the identification of morphosyntactic tools speakers have at their disposal to express their intention i.e. establishing the MG verb moods through a series of tests involving morphology; use of particles; negation; clitic placement; and participation to subordination. In addition, it included the identification of phonological tools speakers have at their disposal to express their intention. In order to establish the MG intonation patterns, we considered different approaches in MG Phonology. One of these approaches was GR ToBi (Arvaniti and Baltazani 2006, accessible at http:// idiom.ucsd.edu/ arvaniti/grtobi.html), a tool for the intonational, prosodic and phonetic representation of Greek spoken corpora, designed to capture Athenian Greek and focusing on a prosodic analysis of phrase based structures. We also considered approaches aiming to explore the relationship between intonation and sentence type interpretation (from a production and perception point of view) such as Kotsifas (2009) and Chaida (2008). Our original research hypothesis included 6 intonation patterns, as outlined in Table 1 below. Note that the adopted intonation patterns were later revised and reduced to 5 .

Table 1.

MG intonation patterns as part of our original methodology

\begin{tabular}{|l|l|l|l|}
\hline $\begin{array}{l}\text { Intonation } \\
\text { Pattern Name }\end{array}$ & Utterance Type & $\begin{array}{l}\text { Additional } \\
\text { characteristics }\end{array}$ & $\begin{array}{l}\text { Final } \\
\text { Boundary }\end{array}$ \\
\hline INT1 & $\begin{array}{l}\text { Assertions } \\
\text { Directives? }\end{array}$ & Broad focus & Low \\
\hline INT2 & $\begin{array}{l}\text { Assertions } \\
\text { Directives? }\end{array}$ & $\begin{array}{l}\text { Narrow focus } \\
\text { Alternative to INT1 }\end{array}$ & Low \\
\hline INT3 & $\begin{array}{l}\text { Content } \\
\text { Interrogatives }\end{array}$ & High \\
\hline INT4 & $\begin{array}{l}\text { Polar } \\
\text { Interrogatives }\end{array}$ & High-Low \\
\hline INT5 & $\begin{array}{l}\text { Directives? } \\
\text { Curses }\end{array}$ & $\begin{array}{l}\text { Assertions-in- } \\
\text { disguise (Rhetorical } \\
\text { Ouestions)? } \\
\text { Miratives? } \\
\text { Wishes? }\end{array}$ & Low-High \\
\hline
\end{tabular}

Our data were collected introspectively, drawn from the linguistic intuitions of the author and compared against examples from reference grammars. The examples were also checked by an informal group of informers ( 6 male and 6 female, aged 12-72, based in different geographical areas of Greece, including 5 male and 4 female from Athens, Thessaloniki, Crete and Patras) and members of the Greek diaspora ( 1 male and 2 female based in London and in New York, USA). The informers were contacted on a regular basis over a period of 9 months, (and less frequently towards the final stages of this work), and were 
individually asked to check the provided examples against their intuition. The sets of examples (covering all MG moods) were separated by mood and function, while brief scenarios were offered for specific cases (e.g. miratives). We were interested in the informants' production instinct (rather than their perception): although for an illocution to be effective it needs to be recognized by an addressee, the addressee might not pay the necessary attention, might not want to recognize the illocution or might lack necessary background information to do so (Levelt 1989). In that sense, illocution is a speaker-centered notion (Levelt 1989, p. 59). Furthermore, sets of examples were compared to internet-based uses. The internet is an easily accessible source of linguistic expressions in use; it is very common for linguists to create web-based informal mini-corpora of specific linguistic phenomena. For example, the interchangeable distribution of $\mu \eta$ with and without a final ' $v$ ' was checked against an internet-based sample of prohibitive uses. For the mini-internet searches, blogs and chat groups were mainly accessed, where the language used is closest to the way current MG users speak; particles and segmental markers were used as the main key-words.

In addition, during the evaluation process, we explored the prosodic contour of instances of uses in each grammatical mood. Prosodic contour, as mentioned earlier, is one of the criteria that allow us to establish a particular illocution. Using a single speaker (the author), we performed a production experiment; by recording examples for each grammatical mood in studio conditions, using a laptop and a portable microphone, we took advantage of Praat's mono recording tool. 85 examples were recorded in total (some in multiple versions) which were edited and analysed using Praat. The evaluation of the results, i.e. the comparison of the Praat illustrations of intonation patterns across different uses and verb moods, made us revise our research hypothesis (and reject the possible $6^{\text {th }}$ intonation pattern originally considered for assertions in disguise, miratives and wishes) and helped us establish the 5 distinct intonation patterns which formally contribute to distinguish different MG illocutions. This approach allowed us to fulfill one of our objectives, i.e. to relate Pragmatics with Phonology, as both form part of the grammatical component.

Each grammatical mood, once identified and established, was analysed considering its propositional and behavioural functions. The results were then classified according to their function.

The term grammatical mood is used in this work as the category which includes "all grammatical elements operating on a situation/proposition, that are not directly concerned with situating an event in the actual world, as conceived by the speaker" (Hengeveld 2004). Basic illocution (also Sentence Type, or Speech Act prototype) is understood as "a coincidence of grammatical structure and conventional conversational use" (Sadock \& Zwicky 1985). Basic illocutions are expressed by the speaker in various forms, using syntactic, morphological and phonological means. 
Below we discuss the MG Subjunctive and its propositional and behavioural functions.

\section{The MG Subjunctive}

Subjunctive is taken to mean a particular grammatical mood with its own semantic identity (modal value, modality). As modality does not form part of this research"1, we define the Modern Greek Subjunctive as a distinct morphosyntactic category by the presence of the particle $v \alpha$ (see also Chondrogianni 2009). Subjunctive exhibits a richness of uses, hence a one-to-one relationship between the form and function cannot be established.

Following Hengeveld et al. (2007), the MG Subjunctive used we describe below have been distinguished into propositional and behavioural uses. Propositional uses are associated with assertive and questioning illocutions. Assertive subtypes consist of declarative and mirative uses, whilst questioning subtypes consist of polar and content interrogatives. Behavioural uses involve speech acts that intend to influence or affect the behaviour of the Addressee and/or others. Behavioural (positive and negative) uses include imperative subtypes (orders), hortative subtypes (exhortations), admonitive subtypes (warnings) and supplicative subtypes (requests for permission). As we show below, the MG Subjunctive's propositional uses consist of wishes, curses, miratives- expressions of disapproval, wondering and expression of uncertainty. Subjunctive exhibits a rich variety of behavioural uses: the particle $v \alpha$ is often explicitly used in order to mitigate the illocutionary force of an utterance; it introduces mitigated directives, mitigated prohibitions and mitigated requests, including supplicatives/ requests for permission.

\section{Propositional Uses of the MG Subjunctive}

\subsection{Introduction}

In this section we discuss propositional subjunctive uses, including wishes and curses, wondering and expression of disapproval.

\footnotetext{
1 Modality involves the "modification of the content of speech acts" (Hengeveld 2004). This research concentrates on "identifying sentences as specific types of speech acts" (i.e. the illocution, as defined by Hengeveld 2004), rather than the modification of the content of speech acts.
} 


\subsection{Wishes}

Wishes in subjunctive denote uses which are not meant to influence the addressee's behaviour. They express the Speaker's desire for a particular state of affairs (which might or might not already be the case) for which the Speaker wishes to happen or to be extended in the future. In that sense, wishes might be possible to be fulfilled, or are currently unfulfilable. In addition, wishes might involve fixed expressions, i.e. wishes that are usually expressed in a formulaic way at ceremonial events including weddings, christenings, anniversaries, funerals etc. In some such cases the verb might be omitted; if it is included in the utterance, though, it is always in subjunctive.

Wishes share the same intonation pattern with assertions²; they are uttered using an intonation pattern INT1 on INT2 (see also Chondrogianni 2012), as part of a schematic intonation pattern illustration we have adopted. INT1 is characterised by broad focus and a high level of the accented syllable (although the nucleus might create variations of this pattern). When narrow focus and a rise from low to the accented syllable applies, as is the case of wishes introduced by

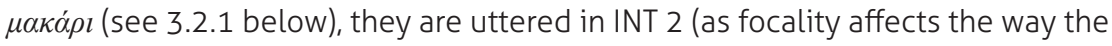
utterance is expressed.).

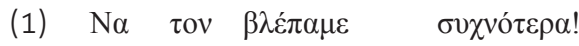

SUB] him see-1P.PS.IPF more often

If only we saw him more often!

Example (1), in the first person plural, expresses a wish for something that is currently not the case (irrealis), with a past imperfect subjunctive used. A Praat illustration of its prosodic contour is presented below.

Example (2) is a typical example of an MG wish3; it expresses self-exhortation. Such utterances are usually expressed in the $1^{\text {st }}$ person singular, in past imperfect tense. It might also be used as a condition if followed by a result, where ' $v \alpha$ ' would have a conditional function. Conditionals do not form part of this research.

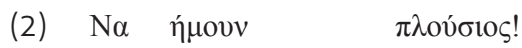

SUB] was-1SG.PS.IPF rich

Were-I rich (If only I were rich!).

$\mathbf{2}$ We recognise that INT1 assertions usually finish with a fall; also, we have observed INT2 assertions finish with a rise. Example (1) ends with a rise and gives the impetus for further research in the wishes' category.

3 Wishes might also be expressed in Hortative, introduced by ac. See also Chondrogianni (2009). 

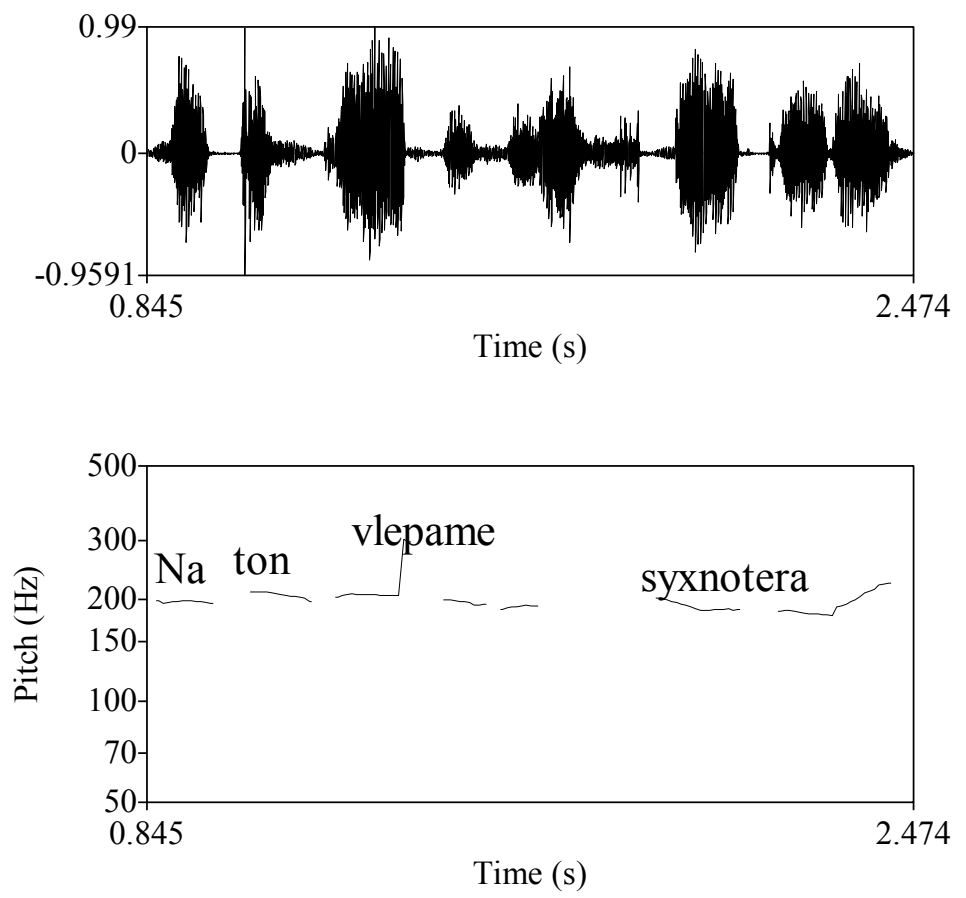

Figure 1. PRAAT illustration of wish (INT1)

Examples (3) and (4) illustrate some fixed expressions of wishes; (3) may typically be uttered in a religious setting as a good-will wish, for example as an expression of gratitude to a benefactor's family. Example (4) is usually addressed to the parents of a child, at birth, christening or other important event.

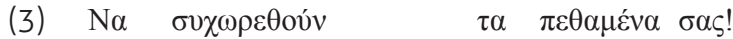

SUB] forgive-3PL.PRF.PASS the dead your

May the dead members of your family be forgiven.

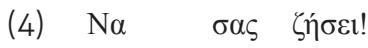

SUB] to you live-3SG.PRF

May (your child) live long.

\subsubsection{Additional Segmental Marking}

Wishes might be marked by special particles, such as $\mu \alpha \kappa \dot{\alpha} \rho l$, which offers the addressee a clue as to how the particular utterance is to be interpreted. When 
uttered, the focal point is on the segmental marker (INT2), as we can also see in fig. 2 below. Such wishes might be fulfilable, now or in the future as in example (5) below, or unfulfilable.

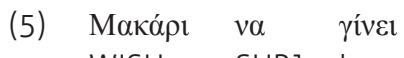
WISH SUB] become-3SG.PRF well I wish he/she gets well.
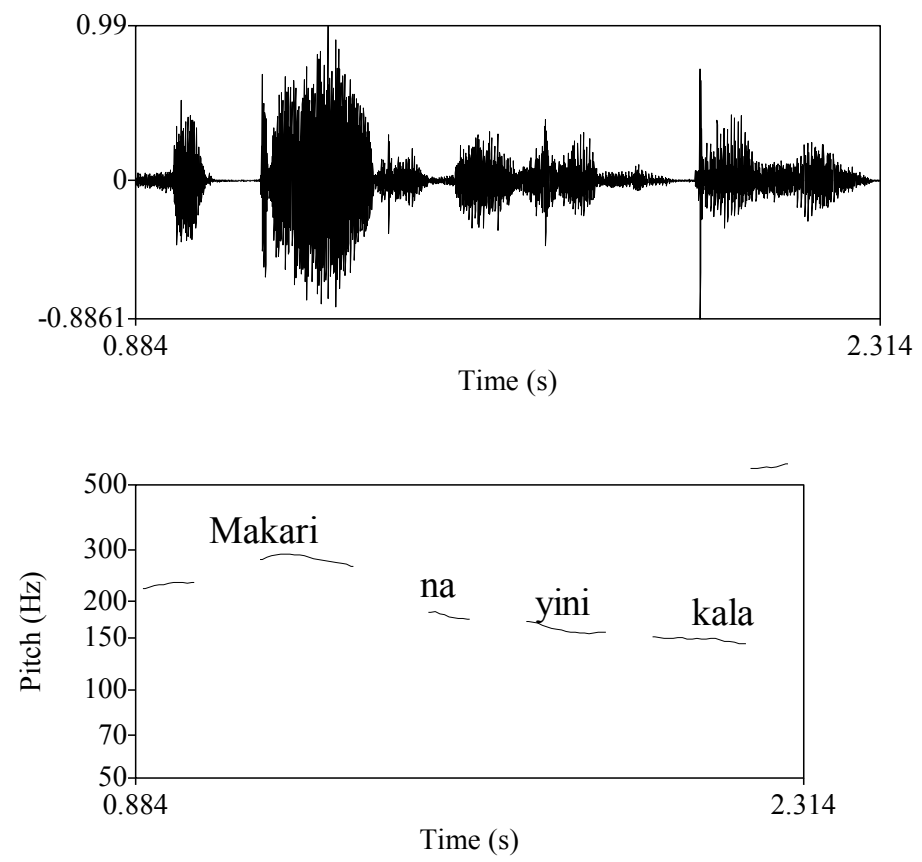

Figure 2. PRAAT illustration of a wish using the segmental marker $\mu \alpha \kappa \alpha$ pı (INT2).

\subsubsection{Summary of the Characteristics of the Basic Illocution Wish}

Wishes in MG are expressed in Subjunctive (or in Hortative), marked by the Subjunctive particle $v \alpha$ (and the optional negation $\mu \eta(v)$ ) and the intonation pattern INT1. When introduced by $\mu \alpha \kappa \dot{\alpha} \rho$, the segmental marker is the focal point of the utterance (INT2). Any person or number might be used, while aspectual differences affect the fulfilability of unfulfilability of a wish. 
Table 2.

Summary of the characteristics of the basic illocution wish

\begin{tabular}{|c|c|}
\hline Type & Propositional \\
\hline Function & Wishes \\
\hline Grammatical Mood & $\begin{array}{l}\text { Subjunctive (particle } v \alpha \text {, optional negation } \mu \eta(v) \text {, optional } \\
\text { segmental marker } \mu \alpha \kappa \alpha \rho) \text { (also Hortative } \alpha \varsigma \text { ) }\end{array}$ \\
\hline Tense & $\begin{array}{l}\text { Present (fulfilable) } \\
\text { Past (unfulfilable) }\end{array}$ \\
\hline Aspect & $\begin{array}{l}\text { Imperfective (Present, Past) } \\
\text { Perfective (Present) }\end{array}$ \\
\hline Person & $1^{\text {st }}, 2^{\text {nd }}$ and $3^{\text {rd }}$ \\
\hline Number & Singular or Plural \\
\hline Intonation Pattern & 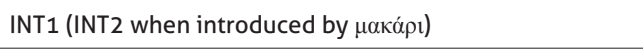 \\
\hline Addressee's response & $\mathrm{N} / \mathrm{A}$ \\
\hline
\end{tabular}

\subsection{Curses}

Curses are a form of negative wish. In main clauses they might be expressed in any number or person, most often using perfective aspect, as we can see from examples (6), (7) and (8).

(6) $\mathrm{N \alpha} \quad \mu \eta v \quad \xi \eta \mu \varepsilon \rho \omega \theta \varepsilon i ́ s$.

SUB] NEG 'see the day downed'-2SG.PR.PRF.PASS

You may not see another day.

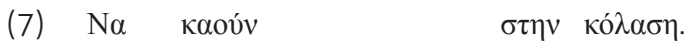

SUB] burn-3PL.PR.PRF.PASS in hell

May they burn in hell.

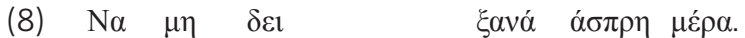

SUB] NEG see-2SG.PR.PRF again white day

May he not experience again a happy day.

\subsubsection{Additional Segmental Marking in Curses}

The use of the segmental marker $\pi$ ov, followed by a Subjunctive, adds a temporary value of immediacy to a curse. This is the case of examples (9) and (10) below.

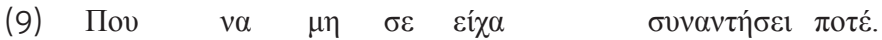

UNWISH SUB] NEG you have-1SG.PS met never

May I had never met you. 


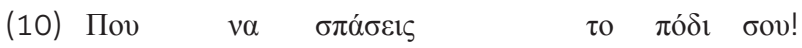
UNWISH SUB] break-2SG.PR.PRF the leg your Break your leg!

Curses are marked by intonation pattern INT5. This pattern starts with a small fall, followed by a rise (and possibly a high plateau), and followed by a fall (and a potential small rise at the end). The boundary is low-high. INT 5 is illustrated in Fig. 3 below, where we observe a small fall after 'pou', a rise after 'na' with a high plateau, a fall following the first (accented) syllable of 'pódi' and a minor rise at 'sou'.

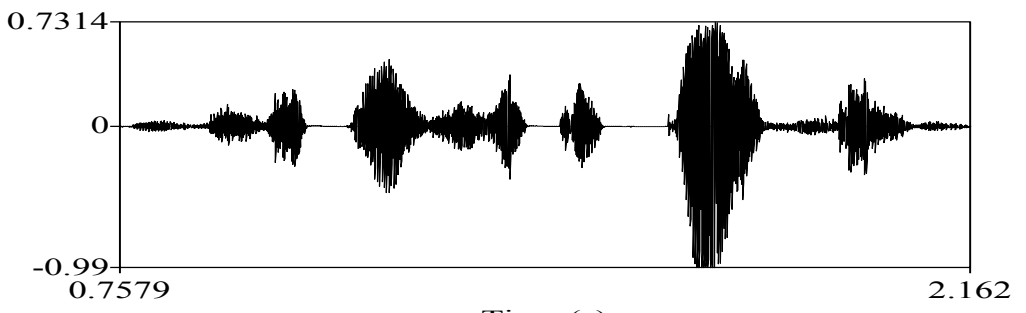

Time (s)

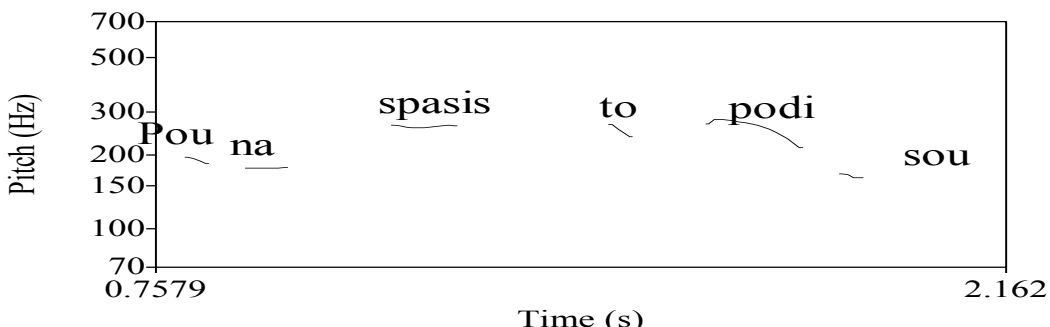

Figure 3. PRAAT illustration of a cursed marked by $\pi$ ov (INT5)

\subsubsection{Summary of the Characteristics of the Basic Illocution Curse}

Curses are marked by the distinct intonation pattern INT5 and the optional use of the segmental marker $\pi$ ov. They occur in Subjunctive, introduced by the particle $v \alpha$, and the optional negation $\mu \eta(v)$. Present tense with perfect aspect characterise their most common uses, as well as $2^{\text {nd }}$ and $3^{\text {rd }}$ person. In the first person they are similar to an oath, often with a complement sentence provided as a means of context. Their characteristics are summarised in Table 3 below. 
Table 3.

Summary of the characteristics of the basic illocution curse

\begin{tabular}{|c|c|}
\hline Type & Propositional \\
\hline Function & Curses (Negative Wishes) \\
\hline Grammatical Mood & $\begin{array}{l}\text { Subjunctive (particle } v \alpha, \text { optional negation } \mu \eta(v) \text {, optional } \\
\text { segmental marker } \pi \mathrm{ov} \text { ) }\end{array}$ \\
\hline Tense & Present \\
\hline Aspect & $\begin{array}{l}\text { Perfective } \\
\text { [Imperfective not excluded but uncommon] }\end{array}$ \\
\hline Person & $2^{\text {nd }}$ and $3^{\text {rd }}\left[1^{\text {st }}\right.$ possible, 'oath' $]$ \\
\hline Number & Singular or Plural \\
\hline Intonation Pattern & INT5 \\
\hline Addressee's response & $\mathrm{N} / \mathrm{A}$ \\
\hline
\end{tabular}

\subsection{Miratives of Disapproval}

When a speaker expresses his/her admiration, surprise or delight through an utterance, effectively they share some information with their addressee. In this type of utterances, it is not so much the content of the utterance itself that is being transmitted, but rather the emotional reaction of the speaker with respect to this content. (Hengeveld et al. 2007). Utterances in this category demonstrate a mixture of declarative and interrogative properties. Approval (positive surprise) is usually expressed in indicative; mirative utterances in subjunctive usually express the speaker's disapproval towards the addressee's taste or choice among others, as in example (11) below.

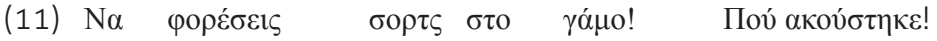

SUB] wear.2SG.PRF shorts to the wedding! (Where was heard!)

To wear shorts at the wedding! This is unheard of!

\subsubsection{Summary Characteristics of Miratives of Disapproval}

Miratives of disapproval are expressed in Subjunctive, introduced by the subjunctive particle $v \alpha$, and optionally by the negation $\mu \eta(v)$, usually in Present Perfect; they are marked by intonation INT3, a pattern typical for, but not restricted to, content interrogatives. Their characteristics are summarised in Table 4 below. 
Table 4.

Summary characteristics of the basic illocution mirative

\begin{tabular}{|c|c|}
\hline Type & Propositional \\
\hline Function & Mirative uses \\
\hline Grammatical Mood & $\begin{array}{l}\text { [Indicative: approval] } \\
\text { Subjunctive (disapproval, particle } v \alpha \text {, optional negation } \mu \eta(v) \text { ) }\end{array}$ \\
\hline Tense & $\begin{array}{l}\text { Present } \\
\text { [Past and Future possible for Indicative] }\end{array}$ \\
\hline Aspect & $\begin{array}{l}\text { Perfective } \\
\text { [ Imperfective not excluded] }\end{array}$ \\
\hline Person & $2^{\text {nd }}$ and $3^{\text {rd }}\left[1^{\text {st }}\right.$ possible $]$ \\
\hline Number & Singular or Plural \\
\hline Intonation Pattern & INT3 \\
\hline Addressee's response & $\mathrm{N} / \mathrm{A}$ \\
\hline
\end{tabular}

\subsection{Wondering}

In most languages subjunctive has a built-in uncertainty/doubt element. Examples (12)-(14) below present question-like utterances, signalling to the addressee the speaker's doubt, uncertainty or speculation, often also expressed as self-directed expressions where the addressee genuinely does not know the answer. Such expressions might appear as polar or content interrogative-like, where no response is expected from the addressee.

(12) $\mathrm{N \alpha} \quad \beta \rho \varepsilon ́ \chi \varepsilon l ;$

SUB] vrehi-3SG.PR.IPF

Is it raining (I wonder)?

Wondering is marked by the combination of the subjunctive with intonation pattern INT4, a pattern also shared with polar interrogatives (which can only be expressed in indicative, where the addressee is expected to confirm the truth of the proposition). Following a gradual fall, we observe a low plateau followed by a rise, with a rise-fall boundary4.

In examples (13) and (14) below, the speaker's wondering is expressed through a deliberative question, in the first person plural and third person

4 Although the rise-fall boundary might not be evident in Fig. 4, its overall picture is consistent with other INT4 examples observed (see also Chondrogianni 2012). 

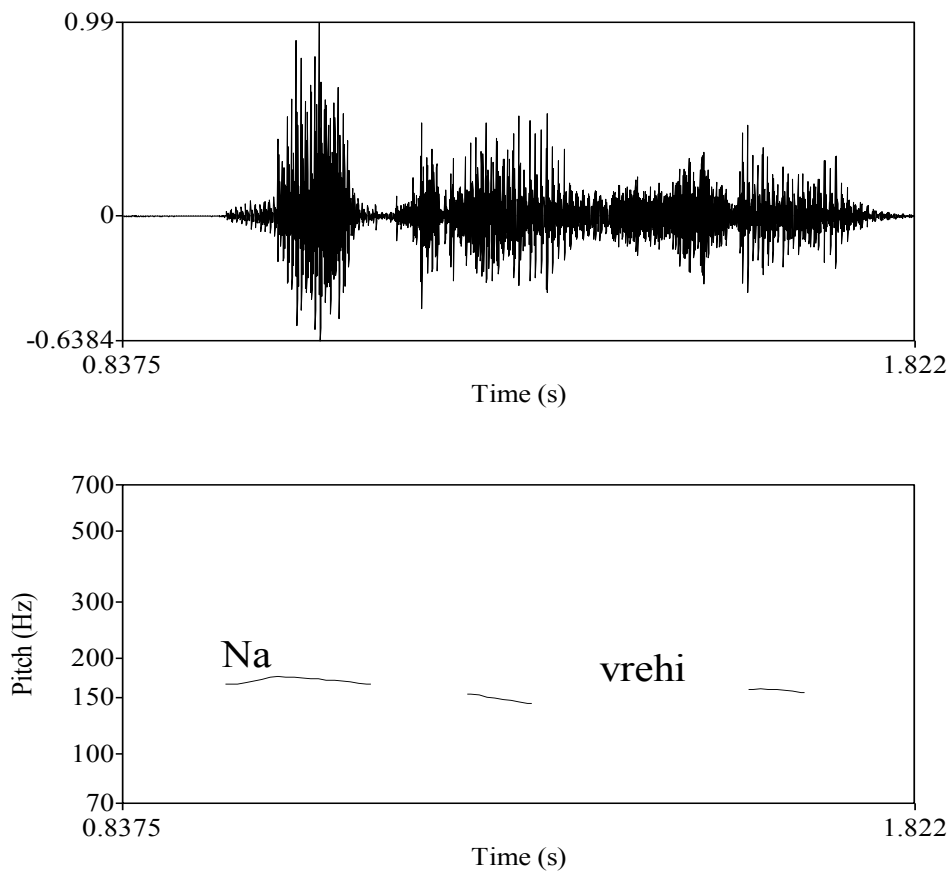

Figure 4. PRAAT illustration of wondering in subjunctive (INT4).

singular respectively, in a content interrogative-like utterance marked by INT3 intonation.

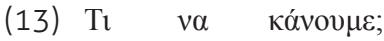

What SUB] do.2PL.IPF

What shall we/can we do?

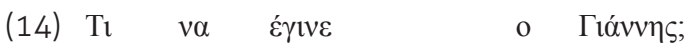
What SUB] become.3SG.IPF the Yannis? What might have happened to Yannis?

\subsubsection{Additional Segmental Marking in Wondering}

A speaker might strengthen the wondering element of their utterance through the use of the segmental marker á $\rho \alpha \varepsilon$, as in example (15), which, similarly to the uncertainty marker í⿴囗⿱一一) below, can combine with either the indicative or the 
subjunctive. The choice of mood is guide by modal criteria; through the use of subjunctive the speaker is less inclined to believe the possibility of the truth of the content of the clause (irrealis). The segmental marker might be placed at the beginning of the utterance, or at the end.

(15) A $\alpha \gamma \varepsilon \quad v \alpha \quad \beta \rho \varepsilon ́ \chi \varepsilon 1 ;$

WOND SUB] rain-3SG.PR.IPF

May be raining, I wonder?

\subsubsection{Summary Characteristics of the Basic Illocution Wondering}

Wondering in MG is expressed either in Subjunctive with or without the use of a particular wondering marker (it can also be expressed in Indicative with compulsory use of the marker $\alpha \rho \alpha \varepsilon)$, marked by intonation INT4 and the use of $3^{\text {rd }}$ person, with $1^{\text {st }}$ person deliberative uses also noted. Their characteristics are summarised in Table 5 below.

Table 5.

Characteristics of the basic illocution wondering

\begin{tabular}{|l|l|}
\hline Function & Wondering \\
\hline Grammatical Mood & $\begin{array}{l}{[\text { Indicative (segmental marker } \alpha \rho \alpha \gamma \varepsilon, \text { optional particle } \theta \alpha, \text { optional }} \\
\text { negation } \delta \varepsilon v)] \\
\text { Subjunctive (particle } v \alpha, \text { or combination of segmental marker } \alpha \text { ó } \alpha \gamma \varepsilon \text { and } \\
v \alpha, \text { optional negation } \mu \eta v)\end{array}$ \\
\hline Scope & Propositional \\
\hline Tense & Present/Past \\
\hline Aspect & Perfective/Imperfective \\
\hline Person & $\begin{array}{l}3^{\text {rd }}\left(1^{\text {st }} \text { for deliberative questions) }\right. \\
2^{\text {nd }} \text { person acceptable for indicative uses only }\end{array}$ \\
\hline Number & Singular or Plural \\
\hline Intonation Pattern & INT4 \\
\hline
\end{tabular}

\subsection{Expression of Strong Sense of Uncertainty in Subjunctive through the Use of the Segmental Marker íows}

A speaker might chose to enhance the built-in uncertainty in subjunctive through

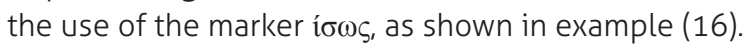




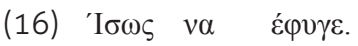

UNC SUB] leave-3SG.PR.PRF

Perhaps he left.

Such uses are marked by the use of intonation pattern INT1, also used in assertions, with a Low boundary, illustrated in Figure 5 below. Note that when

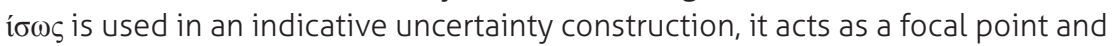
thus the intonation pattern INT2 applies.
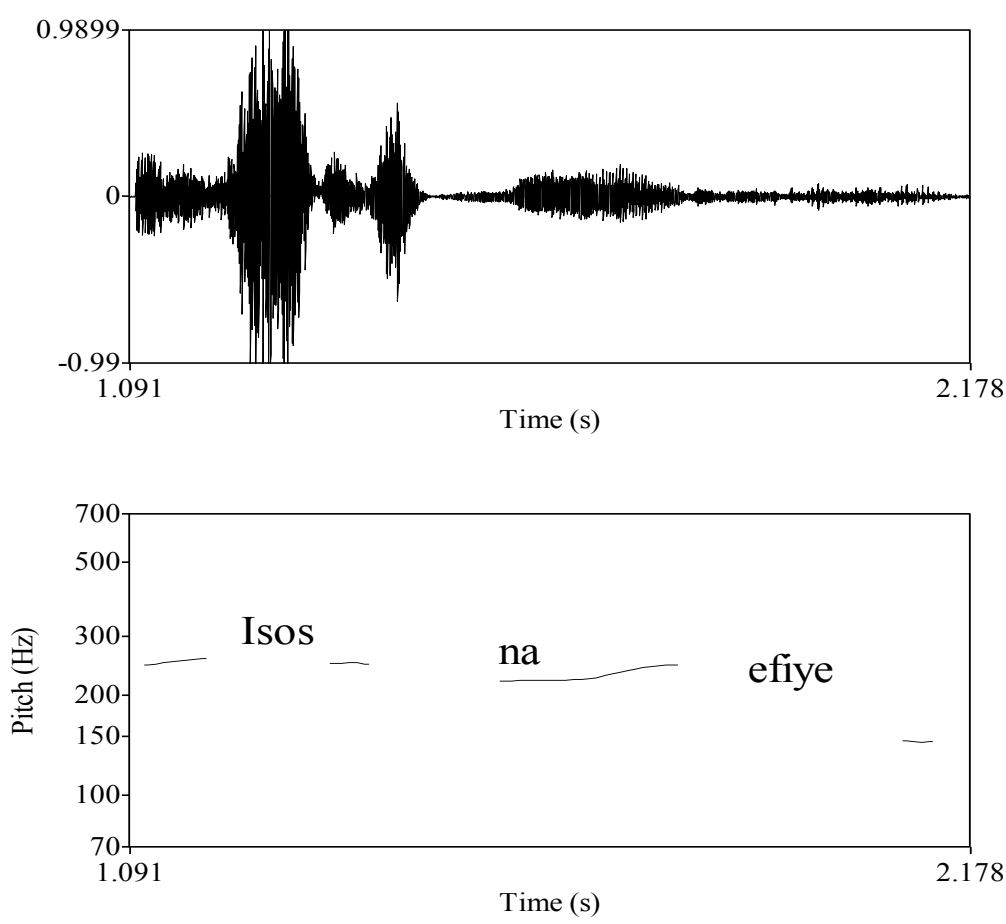

Figure 5. PRAAT illustration of reinforced uncertainty.

\subsubsection{Summary of the Basic Illocution of Uncertainty,

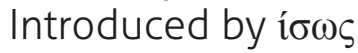

In many ways, wondering in subjunctive, as described in section 3.5 above, involves to some extent the speaker's uncertainty about the validity of the described State of Affairs. Explicitly denoted uncertainty is marked by the particle í $\sigma \omega s$, which, in subjunctive, always takes a fixed position preceding the subjunctive $v \alpha$. Its characteristics are summarised in Table 6 below. 
Table 6.

Characteristics of the basic illocution uncertainty.

\begin{tabular}{|c|c|}
\hline Function & Expression of uncertainty \\
\hline Grammatical Mood & 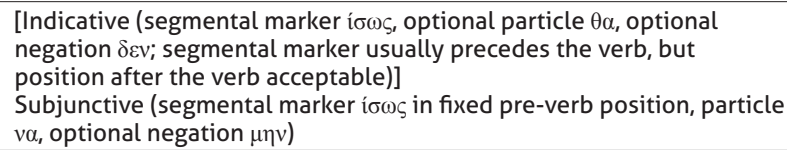 \\
\hline Scope & Propositional \\
\hline Tense & Present/Past [Future in indicative acceptable by some speakers] \\
\hline Aspect & Perfective/Imperfective \\
\hline Person & Any (3rd very common) \\
\hline Number & Singular or Plural \\
\hline Intonation pattern & INT1(Subjunctive) [INT2 in Indicative- focus on uncertainty marker] \\
\hline
\end{tabular}

\section{Behavioural Uses}

We present below a series of uses which involve an attempt by the speaker to alter the addressee's behaviour, including mitigated directives, mitigated prohibitions and supplicatives. The use of subjunctive here lessens (mitigates) the utterance's illocutionary force, allowing the addressee some sense of saving face.

\subsection{Mitigated Directives}

The typical marker of MG subjunctive va acts as a mitigator in behavioural uses; mitigated directives are one of its typical uses (as opposed to imperative nonmitigated uses). Where Perfective is used, as in example (17), directives are to be fulfilled in the immediate future, while imperfective uses (example 18) provide general advice on matters the Speaker considers important.

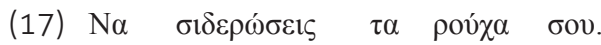

SUB] iron-2SG.PRF the clothes your

You should iron your clothes (now).

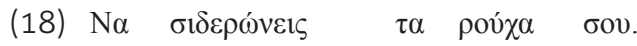

SUB] iron-2SG.PR.IPF the clothes your

You should be ironing your clothes.

Mitigated directives are marked by intonation INT2, as also illustrated in Figure 6 below, with the verb acting as the focal point of the utterance. 

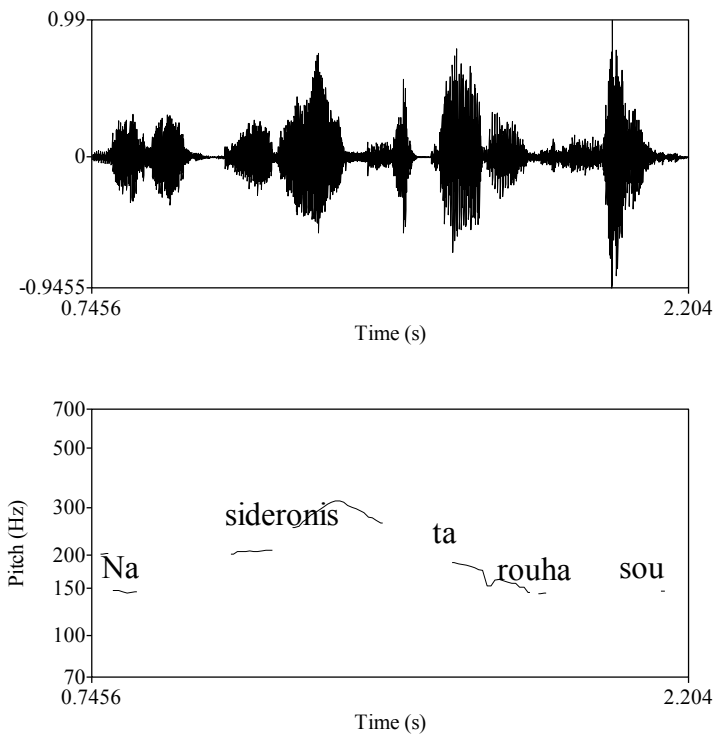

Figure 6. PRAAT illustration of mitigated directive (INT2).

\subsubsection{Summary of Characteristics of Mitigated Directives}

Mitigated directives are expressed in present subjunctive $2^{\text {nd }}$ person singular or plural. INT1 and INT2 intonation patterns apply. Negative uses are excluded from this category, as they are considered separately under the mitigated prohibitions category. Their characteristics are summarised in Table 7 below.

Table 7.

Characteristics of mitigated directives

\begin{tabular}{|l|l|}
\hline Type & Behavioural \\
\hline Function & Mitigated Directives \\
\hline Grammatical Mood & $\begin{array}{l}\text { Subjunctive (particle } v \alpha \text { ) } \\
\text { Excludes negative uses }\end{array}$ \\
\hline Tense & $\begin{array}{l}\text { Present (fulfilable) } \\
\text { Past (unfulfilable) }\end{array}$ \\
\hline Aspect & Perfective/ Imperfective \\
\hline Person & 2nd \\
\hline Number & Singular or Plural \\
\hline Intonation Pattern & INT1/INT2 \\
\hline Addressee's response & N/A \\
\hline
\end{tabular}




\subsection{Mitigated Directives- Encouragement}

A speaker might opt to use a mitigated directive marked by intonation INT4, seemingly giving the impression to the addressee that they have a choice whether to comply or not. Unpleasant suggestions, in particular, trigger the speaker to encourage the addressee to perform an action through a subjunctive question-like utterance, in the $2^{\text {nd }}$ person singular or plural. The use of INT4 further mitigates the impact of the directive, as in example (19), allowing the addressee to save face while encouraged to perform the action.

(19) $\mathrm{N \alpha} \quad \beta \gamma \alpha \dot{\lambda} \varepsilon 1 \varsigma$

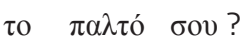

SUB] remove-2SG.PR.PRF the coat your?

Shouldn't you take your coat off?

The summary of the characteristics of this category can be seen in Table 8 below.

Table 8.

Characteristics of the basic illocution mitigated directive-encouragement

\begin{tabular}{|l|l|}
\hline Type & Behavioural \\
\hline Function & Mitigated Directives- encouragement \\
\hline Grammatical Mood & Subjunctive (particle $v \alpha$, optional negation $\mu \eta(v))$ \\
\hline Tense & Present \\
\hline Aspect & Perfective \\
\hline Person & 2 nd \\
\hline Number & Singular or Plural \\
\hline Intonation Pattern & INT4 \\
\hline Addressee's response & {$[$ Consent] } \\
\hline
\end{tabular}

\subsection{Mitigated Prohibitions}

In our view, when $\mu \eta(v)$ is used independently, i.e. without being preceded by the subjunctive particle $v \alpha$, it acts as the MG prohibitive marker (see also Chondrogianni 2011). By opting to choose a structure where $v \alpha$ precedes $\mu \eta(v)$ (in a $2^{\text {nd }}$ person singular or plural utterance) the speaker makes a choice to mitigate the impact of a prohibition, as is the case of examples (21) and (22). The presence of the particle $v \alpha$ is absolutely necessary for a prohibition to be mitigated. Intonation INT2 applies, with the prohibitive marker (negation) acting as the focal point. 


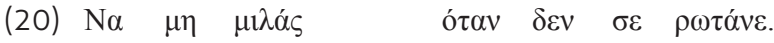

SUB] PRH speak-2SG.IPF when NEG you ask-3PL.IPF

You shouldn't speak when you are not asked.

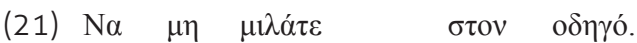

SUB] PRH speak-2PL.IPF to the driver

You shouldn't speak to the driver.

The characteristics of this category are summarised in Table 9 below.

Table 9.

Characteristics of mitigated prohibitions

\begin{tabular}{|l|l|}
\hline Type & Behavioural \\
\hline Function & Mitigated Prohibitions \\
\hline Grammatical Mood & Subjunctive (particle $v \alpha$, compulsory negation $\mu \eta(v))$ \\
\hline Tense & Present \\
\hline Aspect & $\begin{array}{l}\text { Imperfective } \\
\text { (Perfective possible) }\end{array}$ \\
\hline Person & 2nd \\
\hline Number & Singular or Plural \\
\hline Intonation Pattern & INT2 \\
\hline Addressee's response & {$[$ Consent] } \\
\hline
\end{tabular}

\subsection{Supplicatives- Requests for Permission}

Requests for permission in Modern Greek subjunctive often have an interrogative like intonation, but not an interrogative function: the speaker does not ask for the propositional content of the question to be assigned a value true or false. In a way, the process of a question is reversed. Examples (22) and (23) remind us of the use of modal 'may' in English. Such utterances are expressed in the $1^{\text {st }}$ person singular or plural. Intonation INT4 applies.

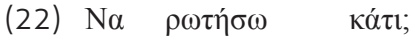

SUB] ask.1SG.PRF something?

May I ask something?

(23) $\mathrm{N \alpha} \quad \pi \lambda v ́ v \omega \quad \tau \alpha \quad \pi$ ió $\tau$;

SUB] wash.1SG.PRF the dishes?

May I wash the dishes? 
The supplicatives' main characteristics are summarized in Table 10 below.

Table 10.

Characteristics of supplicatives- requests for permission

\begin{tabular}{|l|l|}
\hline Type & Behavioural \\
\hline Function & Supplicatives- Requests for permission \\
\hline Grammatical Mood & Subjunctive (particle $v \alpha$, optional negation $\mu \eta(v))$ \\
\hline Tense & Present (Past further mitigates the utterance) \\
\hline Aspect & Perfective \\
\hline Person & $1^{\text {st }}$ \\
\hline Number & Singular or Plural \\
\hline Intonation Pattern & INT4 \\
\hline Addressee's response & Consent \\
\hline
\end{tabular}

\section{Conclusion}

In this paper we discussed the pragmatic functions associated with the Modern Greek Subjunctive. We differentiated between propositional and behavioural uses and presented a comprehensive classification of each particular use. We showed that Subjunctive propositional uses include wishes, which might be fulfilable or unfulfilable, optionally introduced by the segmental marker $\mu \alpha \kappa \alpha \dot{\rho} \rho$; curses, marked by a distinct intonation pattern, optionally introduced by $\pi$ ov; wondering uses, optionally introduced by the segmental marker $\alpha \rho \alpha \gamma$; mirative uses (of disapproval), marked by intonation; and expressions of uncertainty

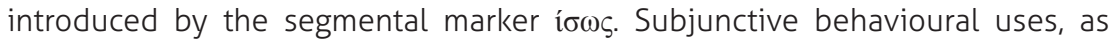
presented above, include mitigated directives, marked by intonation and use of the 2 nd person; mitigated prohibitions, where the presence of negation $\mu \eta(v)$ is obligatory; mitigated directives-encouragement, marked by intonation, with the expectation of a consent response; and supplicative uses (requests for permission), expressed in the $1^{\text {st }}$ person singular or plural, marked by intonation. 


\section{References}

Arvaniti, A. 2007. Greek Phonetics: The State of the Art, Journal of Greek Linguistics 8: 97-208.

Arvaniti, A. and Baltazani, M. 2005. Intonation analysis and prosodic annotation of Greek spoken corpora. In Sun-Ah, J. (ed.) Prosodic Typology: The Phonology of Intonation and Phrasing, 84-117, Oxford: Oxford University Press.

Auwera, J. van. 2006. Why languages prefer prohibitives. Journal of Foreign Languages 161, Vol.1., 2-25.

Baltazani, M. 2007. Introduction to Phonetics, Translation into Greek and adaptation of Ladefoged, P. A Course in Phonetics, Athens: Patakis.

Chondrogianni, M. 1997. The Subjunctive in Modern Greek: A Functional Grammar Perspective. In Butler, C.S., Connolly, J.H., Gatward, R.A. and Vismans, R.M. (eds.) A Fund of Ideas: Studies in Language and Language in Use, Amsterdam: IFOTT.

Chondrogianni, M. 2009. The Indicative in Modern Greek. In Tsangalidis, A. (ed.) Selected papers from the $18^{\text {th }}$ International Symposium on Theoretical and Applied Linguistics (18th ISTAL, May 2007), 123-130, Thessaloniki: Monochromia

Chondrogianni, M. 2011 The pragmatics of the modal particles $v \alpha, \theta \alpha$, $\alpha \varsigma$ and $\mu \eta(v)$. In Chatzopoulou, K., loannidou, A. and Yoon, S. (eds.) Proceedings of the $9^{\text {th }}$ international conference on Greek linguistics, 322-332, Chicago, Illinois, USA, University of Chicago.

Chondrogianni, M. 2011. The Pragmatics of Prohibitive and Hortative in MG. In Kitis, E., Lavidas, N., Topintzi, N. and Tsangalidis, T. (eds.) Selected papers from the 19th International Symposium on Theoretical and Applied Linguistics (19th ISTAL, April 2009) 135-142, Thessaloniki: Monochromia. 
Chondrogianni, M. 2012 Basic illocutions of the MG indicative. In Gavriilidou, Z., Efthymiou, A., Thomadaki, E. and Kambakis-Vougiouklis, P. (eds.) Selected papers of the $10^{\text {th }}$ ICGL, 223-234, Democritus University of Thrace, Komotini, Greece.

Christidis, A.P. 1986. On the Modern Greek Deictic Particle na, Studies in Greek Linguistics 6, Proceedings of the $5^{\text {th }}$ Annual Conference on Greek Linguistics, May 1985, 221-241, Thessaloniki: Kyriakidis.

Clairis, C., and Babiniotis, G. 1999. Grammar of Modern Greek: The verb, Athens: Ellinika Grammata.

De Groot, C. 2010. Mood in Hungarian. In Rothestein, B. and Tieroff, R. (eds.) Mood in the languages of Europe, Amsterdam: Benjamins.

Economidou-Kogetsidi, M. 2002. Request strategies in English and Greek: Observations from an Airline's call centre, Nottingham: Linguistic Circular 17.

Giannakidou, A. 2007. Time for mood: the subjunctive revisited. Ms., University of Chicago.

Hannay, M. and Hengeveld, K. 2009. Functional Discourse Grammar: Pragmatic aspects. In Verschueren, J. and Östman, J. (eds.) Handbook of Pragmatics, Amsterdam: Benjamins.

Hengeveld, K. 2004. Illocution, Mood and Modality. In Booij, G.E., Lehman, C., Mugdan, J. and Skopeteas, S. (eds.) Morphology: An International Handbook on Inflection and Word-Formation, Vol. 2, Berlin: De Gruyter.

Hengeveld, K. and Mackenzie, J.L. 2008. Functional Discourse Grammar: A typologically-based theory of language structure, Oxford: Oxford University Press.

Hengeveld, K., Nazareth Bechara, E., Gomes Camacho, R., Regina Guerra, A., Peres de Oliveira, T., Penhavel, E., Goreti Pezatti, E., Santana, L., de Souza, E.R.F. and Teixeira, M.L. 2007. Basic illocutions in the native languages of Brazil. In Mattos Dall'Aglio Hattnher, M. and Hengeveld, K. (eds.) Advances in Functional Discourse Grammar, Special issue of Alfa-Revista de Lingüística 51.2: 73-90.

Holton, D., Mackridge, P. and Philippaki-Warburton, I. 1997. Greek: A comprehensive grammar of the Modern Greek language, London: Routledge. 
Joseph, B.D. and Janda, R.D. 1999. The Modern Greek Negator $\mu \eta(v)(-)$ as a Morphological Constellation. In Babiniotis, G. (ed) Greek Linguistics: Proceedings of the $3^{\text {rd }}$ International Conference on Greek Linguistics, 341-351, Athens: Ellinika Grammata.

Joseph, B.D. and Philippaki-Warburton, I. 1987. Modern Greek, Guilford: Biddles Ltd.

Levinson, D. 2005. Aspect in Negative imperative and genitive of negation: a unified analysis of two phenomena in Slavic languages, MS, Stanford University.

Nespor, M. and Vogel, I. 1986. Prosodic Phonology, Dordrecht: Foris.

Noonan, M. 1985. Complementation. In Shopin, T. (ed.) Language Typology and Syntactic Description, Vol. II, Cambridge: Cambridge University Press.

Pavlidou, T. 1991. Cooperation and the choice of linguistics means: some evidence from the use of Subjunctive in Modern Greek, Journal of Pragmatics 15, 11-42.

Platzack, C. and Rosengren, I. 1998. On the subject of imperatives: A minimalist account of the imperative clause, The Journal of Comparative Germanic Linguistics 1, 177-224.

Philippaki-Warburton, I. 1994. The Subjunctive mood and the syntactic status of the particle na in Modern Greek, Folia Linguistica XXVIII/3-4, 299-328.

Philippaki-Warburton, I. 1998. Functional categories and Modern Greek syntax, The Linguistic Review 15, 159-186.

Philippaki-Warburton, I. and Spyropoulos, V. 2004. A change of mood: the development of the Greek mood system, Linguistics 42.2, 791-817.

Philippaki-Warburton, I. and Veloudis, I. 1985. The subjunctive in complement clauses, Studies in Modern Greek Linguistics 5, Proceedings of the $5^{\text {th }}$ Annual Meeting of Greek Linguistics, May 1984, Thessaloniki: Kyriakidis.

Quer, J. (ed). 2009. The distribution and interpretation of indicative and subjunctive, Special issue, Lingua 120.

Risselada, R. 1990. Illocutionary function and functional illocution, Working papers in Functional Grammar 34, Amsterdam: University of Amsterdam. 
Sadock, J.M. and Zwicky, A.M. 1985. Speech Act Distinctions in Syntax. In Shopen, T. (ed.) Language Typology and Syntactic Description, Vol. I, Cambridge: Cambridge University Press.

Tsangalidis, A. 1999. What is the subjunctive? Verbal categories in Modern Greek dictionaries and grammars, Studies in Modern Greek Linguistics 20: 543-554, Thessaloniki: Kyriakidis.

Tsangalidis, A. 2002. Criteria for Modalhood: the case of the Modern Greek modal particles, Studies in Modern Greek Linguistics 21: 759-770, Thessaloniki: Kyriakidis.

Tzartzanos, A. 1946/1989. Modern Greek Syntax, 2 vols, Thessaloniki: Kyriakidis.

Veloudis, I. 1987. "mi figo, mi figis, "mi figi.../ na mi figo, na mi figis, na mi figi and the grammaticalisation of directness, Studies in Greek Linguistics 8: 293-310, Thessaloniki: Kyriakidis.

Veloudis, I. and Philippaki-Warburton, I. 1983. The subjunctive in Modern Greek, Studies in Greek Linguistics 4: 151-168, Thessaloniki: Kyriakidis. 
Major Trends in Theoretical and Applied Linguistics 